\title{
GCU
}

Glasgow Caledonian

University

University for the Common Good

\section{The effect of SAP on volumetric changes and microstructural alterations in PC-GGBS matrices}

Almeida, Fernando C.R.; Rostami, Rohollah ; Klemm, Agnieszka J.

Published in:

3rd International Conference on the Application of Superabsorbent Polymers (SAP) and Other New Admixtures Towards Smart Concrete

DOI:

10.1007/978-3-030-33342-3_11

Publication date:

2020

Document Version

Author accepted manuscript

Link to publication in ResearchOnline

Citation for published version (Harvard):

Almeida, FCR, Rostami, R \& Klemm, AJ 2020, The effect of SAP on volumetric changes and microstructural alterations in PC-GGBS matrices. in WP Boshoff, R Combrinck, V Mechtcherine \& M Wyrzykowski (eds), 3rd International Conference on the Application of Superabsorbent Polymers (SAP) and Other New Admixtures Towards Smart Concrete. RILEM Bookseries, no. 1, vol. 24, Springer, pp. 97-105, 3rd International Conference on the Application of Superabsorbent Polymers and Other New Admixtures Towards Smart Concrete, Skukuza, South Africa, 25/11/19. https://doi.org/10.1007/978-3-030-33342-3_11

\section{General rights}

Copyright and moral rights for the publications made accessible in the public portal are retained by the authors and/or other copyright owners and it is a condition of accessing publications that users recognise and abide by the legal requirements associated with these rights.

Take down policy

If you believe that this document breaches copyright please view our takedown policy at https://edshare.gcu.ac.uk/id/eprint/5179 for details of how to contact us. 


\title{
The effect of SAP on volumetric changes and microstructural alterations in PC-GGBS matrices
}

\author{
Fernando C.R. Almeida ${ }^{1,2}$, Rohollah Rostami ${ }^{3}$, and Agnieszka J. Klemm ${ }^{4}$ \\ ${ }^{1}$ Department of Civil Engineering, Federal University of São Carlos, São Carlos, SP, \\ 13565-905, Brazil; PH (55) 1633519659; email: almeida@ufscar.br \\ ${ }^{2}$ Laboratory of Construction Materials, Institute for Technological Research - IPT, São \\ Paulo, SP, 05508-901, Brazil; PH (55) 1137674969; email: fernandocouto@ipt.br \\ ${ }^{3}$ School of Computing, Engineering and Built Environment, Glasgow Caledonian \\ University, Glasgow G4 0BA, UK; email: rohollah.rostami@gcu.ac.uk \\ ${ }^{4}$ School of Computing, Engineering and Built Environment, Glasgow Caledonian \\ University, Glasgow G4 0BA, UK; PH (44) 01413313892; email: a.klemm@gcu.ac.uk
}

\begin{abstract}
Despite their growing popularity in construction, cement-based materials containing ground granulated blast-furnace slag (GGBS) may suffer from various deteriorative actions, including development of early cracks caused by shrinkage processes. Moreover, the degree of GGBS reaction (at later stages) can be limited by lack of space already filled by early products of Portland cement (PC) hydration. In attempt to reduce these negative effects, Superabsorbent polymers (SAP) can be used as internal curing agents and facilitate hydration processes. This paper intends to evaluate and correlate shrinkage behaviour and microstructural features of SAP-GGBS mortars during the first 90 days. Six sets of mortars (with $0 \%$ and 50\% GGBS) modified by two SAPs were analysed. Autogenous, plastic and drying shrinkages were tested, and microstructural characteristics were analysed by the MIP technique. The experimental results showed significant effect of SAPs on shrinkage reduction in GGBS matrices. The paper argues that deposition of later GGBS hydration products in pores below 20 $\mathrm{nm}$, triggered by SAP water, leads to a relative expansion of SAP-PC-GGBS mortars. In this context, the role of SAPs in GGBS-PC matrices is twofold: firstly, a provision of additional water for hydration and, secondly, a provision of the required space for later products formation.
\end{abstract}

Keywords: superabsorbent polymers, GGBS, hydration, shrinkage, porosity

\section{INTRODUCTION}

Superabsorbent polymers (SAP) are widely recognised as a new type of admixture, which can provide additional water for internal curing of cementitious materials during setting and hardening processes (Mechtcherine \& Reinhardt, 2012; Wyrzykowski, Igarashi, Lura, \& Mechtcherine, 2018). The performance of SAP-modified concrete depends not only on its intrinsic characteristics (shape, size, crosslinking density, chemical structure) but also on the external stimuli surrounding the polymer. In this context, both absorption capacity and sorption kinetics are highly influenced by $\mathrm{pH}$ and 
ionic concentration of a pore solution, given by the type of binder used (Almeida \& Klemm, 2018a; Snoeck, Jensen, \& De Belie, 2015).

Addition of ground granulated blast-furnace slag (GGBS) can affect the rate and extend of cementitious reactions due to its filler effect (Scrivener, Lothenbach, et al., 2015). GGBS reaction is slower than the reaction of clinker phases from Portland cement (PC), and depends on the chemical composition, fineness, glass content as well as on the composition of interacting solution. Although there is still no consensus on the mechanisms controlling PC-GGBS hydration kinetics, especially beyond one day, it is becoming clear that the amount of space available is a critical factor (Berodier \& Scrivener, 2015; Scrivener, Juilland, \& Monteiro, 2015).

Thus, in addition to the prolonged water provision, a collapsed SAP has the potential to provide more room for the deposition of later GGBS hydration products (Almeida \& Klemm, 2018b). Therefore, this paper aims to evaluate the effect of SAP on volumetric changes and microstructural alterations in PC-GGBS mortars, by correlating shrinkage results and pore size distributions up to 90 days.

\section{EXPERIMENTAL PROGRAMME}

Six mortar compositions have been designed for the experimental programme, with different binders (Portland cement - PC, CEM I 52.5N; and 50\% PC, 50\% GGBS) and two SAPs. Chemical and physical characteristics of PC and GGBS are listed in Table 1 .

Table 1. Chemical and physical characteristics of PC and GGBS.

\begin{tabular}{ccccccccccc}
\hline & $\begin{array}{c}\mathrm{SiO}_{2} \\
(\%)\end{array}$ & $\begin{array}{c}\mathrm{Al}_{2} \mathrm{O}_{3} \\
(\%)\end{array}$ & $\begin{array}{c}\mathrm{Fe}_{2} \mathrm{O}_{3} \\
(\%)\end{array}$ & $\begin{array}{c}\mathrm{CaO} \\
(\%)\end{array}$ & $\begin{array}{c}\mathrm{MgO} \\
(\%)\end{array}$ & $\begin{array}{c}\mathrm{SO}_{3} \\
(\%)\end{array}$ & $\begin{array}{c}\mathrm{Na}_{2} \mathrm{O} \\
(\%)\end{array}$ & $\begin{array}{c}\mathrm{K}_{2} \mathrm{O} \\
(\%)\end{array}$ & $\begin{array}{c}\text { LOI } \\
(\%)\end{array}$ & $\begin{array}{c}\text { Fineness } \\
\left(\mathrm{m}^{2} / \mathrm{kg}\right)\end{array}$ \\
\hline $\mathrm{PC}$ & 20.1 & 4.9 & 2.7 & 62.4 & 2.2 & 3.2 & 0.3 & 0.6 & 2.8 & 410 \\
\hline $\mathrm{GGBS}$ & 34.5 & 13.1 & 0.2 & 38.5 & 9.7 & 0.4 & 0.2 & 0.6 & 0.6 & 390 \\
\hline
\end{tabular}

Two types of SAPs (A and B), provided by BASF Construction Chemicals GmbH, have been used in the proportion of $0.25 \%$ by mass of binder (Table 2 ). Full characterization of SAPs used in this study, including kinetics sorption analysis, can be found in Almeida \& Klemm (2018a).

Table 2. Characterization of SAPs.

\begin{tabular}{lcc}
\hline Properties & SAP A & SAP B \\
\hline Type of polymer & $\begin{array}{c}\text { copolymer of acrylamide } \\
\text { and acrylic acid }\end{array}$ & $\begin{array}{c}\text { modified } \\
\text { polyacrylamide }\end{array}$ \\
\hline Particles size $(\mu \mathrm{m})$ & $30-140$ & $30-140$ \\
\hline WAC $^{1}$ deionized water (by tea-bag test) & $340 \mathrm{~g} / \mathrm{g}$ & $290 \mathrm{~g} / \mathrm{g}$ \\
\hline Time to get max WAC ${ }^{1}$ (by tea-bag test) & $2880 \mathrm{~min}$ & $30 \mathrm{~min}$ \\
\hline WAC $^{1}$ mixing water $($ by flow table) & $28 \mathrm{~g} / \mathrm{g}$ & $24 \mathrm{~g} / \mathrm{g}$ \\
\hline${ }^{1} \mathrm{WAC}^{\text {}}$ water absorption capacity &
\end{tabular}


Mortars have been prepared in the proportion of 1:2 (binder:sand) and with total water/binder ratio (w/b) of 0.5 . The second stage of research was focused on drying shrinkage analysis. Mortars used in this part had different w/b as shown in Table 3. Fine sand used as fine aggregate contained at least $90 \%$ of particles smaller than $0.425 \mathrm{~mm}$ (BS EN 13139, 2013). Table 3 shows nomenclature of mortar samples used in this experimental programme.

Table 3. Mixture composition of mortar samples.

\begin{tabular}{cccccc}
\hline $\begin{array}{c}\text { Samples } \\
\text { name }\end{array}$ & $\begin{array}{c}\text { SAP } \\
\text { composition }\end{array}$ & $\begin{array}{c}\text { Binder } \\
\text { composition }\end{array}$ & $\begin{array}{c}\text { Binder : Sand } \\
\text { proportion }\end{array}$ & $\begin{array}{c}\text { Total } \\
\text { w/b ratio }\end{array}$ & $\begin{array}{c}\text { DS total } \\
\text { w/b ratio }\end{array}$ \\
\hline R0 & - & $100 \%$ PC; $0 \%$ GGBS & $1: 2$ & 0.50 & 0.52 \\
\hline A0 & SAP A & $100 \%$ PC; $0 \%$ GGBS & $1: 2$ & 0.50 & 0.58 \\
\hline B0 & SAP B & $100 \%$ PC; $0 \%$ GGBS & $1: 2$ & 0.50 & 0.58 \\
\hline R50 & - & $50 \%$ PC; $50 \%$ GGBS & $1: 2$ & 0.50 & 0.52 \\
\hline A50 & SAP A & $50 \%$ PC; $50 \%$ GGBS & $1: 2$ & 0.50 & 0.58 \\
\hline B50 & SAP B & $50 \%$ PC; $50 \%$ GGBS & $1: 2$ & 0.50 & 0.58 \\
\hline
\end{tabular}

${ }^{1}$ Total $\mathrm{w} / \mathrm{b}$ ratio used in samples for tests of plastic shrinkage, autogenous shrinkage and MIP;

${ }^{2}$ Total $\mathrm{w} / \mathrm{b}$ ratio used in samples for tests of drying shrinkage.

Plastic shrinkage (PS) was evaluated by measuring cracking widths of restrained mortars using a steel form insert ASTM C1579-13 (2013). Three restrained prismatic specimens of $50 \times 50 \times 240 \mathrm{~mm}^{3}$ were produced for each mortar mix, and stored in a ventilation chamber $\left(\mathrm{T}=40 \pm 3^{\circ} \mathrm{C}\right.$ and $\left.\mathrm{RH}=15 \pm 10 \%\right)$ for $24 \mathrm{~h}$ (Almeida, Klemm, \& Corinaldesi, 2018). After demoulding, cracks on the free surface of specimens were analysed by optical microscopy and measured by the ImageJ software.

Autogenous shrinkage (AS) was tested in triplicate by the sealed corrugated tubes method ASTM C1698-09 (2009) from the final setting time to 90 days. Setting times were determined according to BS EN 196-3 and the results are shown in Almeida \& Klemm (2016).

Drying shrinkage (DS) testing was performed on prismatic specimens ( $75 \times 75$ x 280 $\mathrm{mm}^{3}$ ) according to BS ISO 1920-8 (2009). Samples were demoulded after $24 \mathrm{~h}$ and left drying in laboratory environment $\left(\mathrm{T}=21 \pm 2^{\circ} \mathrm{C}\right.$ and $\left.\mathrm{RH}=40 \pm 5 \%\right)$ for 90 days. Length was measured daily in the first 28 days, and weekly in the following two months.

Microstructural features were evaluated after unsealed curing in climate chamber $\left(\mathrm{T}=21 \pm 2{ }^{\circ} \mathrm{C}\right.$ and $\mathrm{RH}=40 \pm 5 \%$ ) at 7, 28 and 90 days. Microstructural characteristics (total porosity (\%) and pore size distribution (nm)) were analysed by the Mercury Intrusion Porosimetry (MIP) technique.

\section{RESULTS AND DISCUSSIONS}

Figure 2 shows the representative micrographs of cracked surfaces of each PC-GGBSSAP mortar subjected to plastic shrinkage (PS) testing. All reference samples (without SAP) displayed cracks visible to the naked eye (greater than $0.1 \mathrm{~mm}$ width), while in SAPs mortars, such cracks appeared only for B50 specimen. Due to higher absorption capacity of SAP A (Table 2) more water is available for early cementitious reactions 
leading to smaller cracking susceptibility (Almeida et al., 2018). However, when compared to the reference specimens both SAPs significantly reduced widths of plastic shrinkage cracking up to $90 \%$.

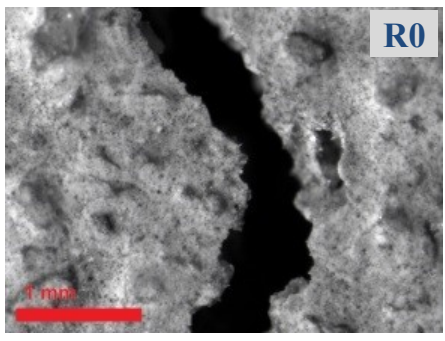

$\mathrm{R} 0=0.577 \pm 0.173 \mathrm{~mm}$

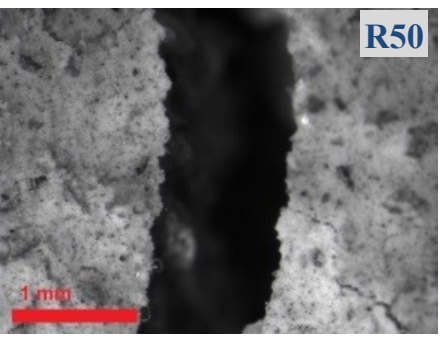

$\mathrm{R} 50=0.972 \pm 0.070 \mathrm{~mm}$

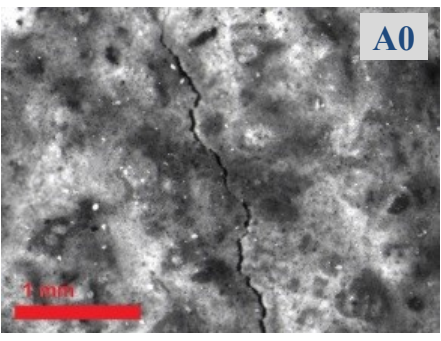

$\mathrm{A} 0=0.039 \pm 0.013 \mathrm{~mm}$

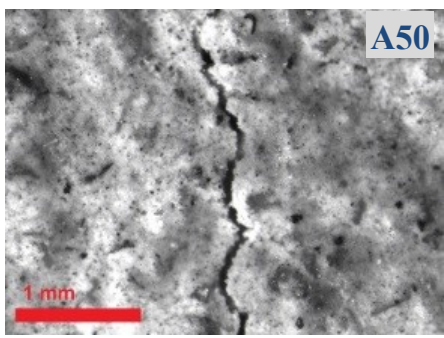

$\mathrm{A} 50=0.079 \pm 0.016 \mathrm{~mm}$

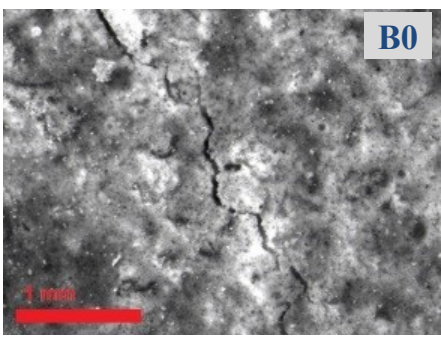

$\mathrm{B} 0=0.044 \pm 0.014 \mathrm{~mm}$

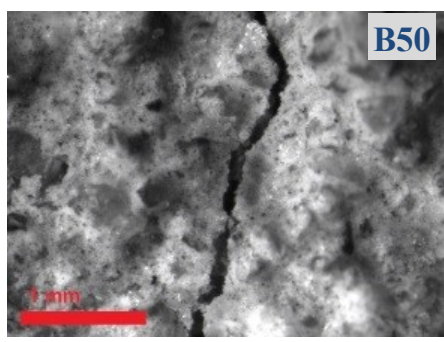

$\mathrm{B} 50=0.126 \pm 0.027 \mathrm{~mm}$

Figure 2. Average of plastic shrinkage cracking widths formed in each mortar.

Figure 3 shows results of autogenous shrinkage (AS) measurements. Overall, SAPs reduced AS in all mortars, with and without GGBS, when compared to the reference samples. Again, SAP A seemed to be more efficient in reduction of autogenous shrinkage owing to its higher and slower WAC, i.e., more water is available in the system that is gradually and slowly released. As a result, mortars with SAP A had the lowest values of shrinkage in comparison with the other samples at 90 days. Moreover, SAP A had a different behaviour than SAP B, showing an initial swelling in the first week and competing with the early-age shrinkage. As a result, SAP A either counteracts (A0) or decreases (A50) shrinkage. Some studies using pure PC systems showed filling of SAP pores by calcium hydroxide during the first week (Justs et al., 2015).

GGBS addition has an impact on performance of SAP mortars over time. The efficiency of SAP in reducing AS is improved by incorporation of slag, since GGBS increases autogenous shrinkage (Lee, Lee, Lee, \& Kim, 2006). Also, plain SAPmortars slightly shrank (B0) or after initial "dormant period" swelled a little (A0). After that, no volumetric changes took place (A0) or shrinkage proceeded at the same pace as in the reference sample (B0).

However, in PC-GGBS-SAP mortars a slight swelling was noticed after a maximum shrinkage around -200 and $-100 \mathrm{~mm} / \mathrm{m}$ for B50 and A50, respectively. Other studies have also confirmed an expansion in systems containing shrinkage reducing admixtures (Snoeck et al., 2015). This effect of "relative" expansion took place after the second week and was more pronounced for higher GGBS contents (Almeida \& Klemm, 2018b). This is related to the beginning of GGBS hydration facilitated by the presence of SAP as water supplier in smaller pores. 


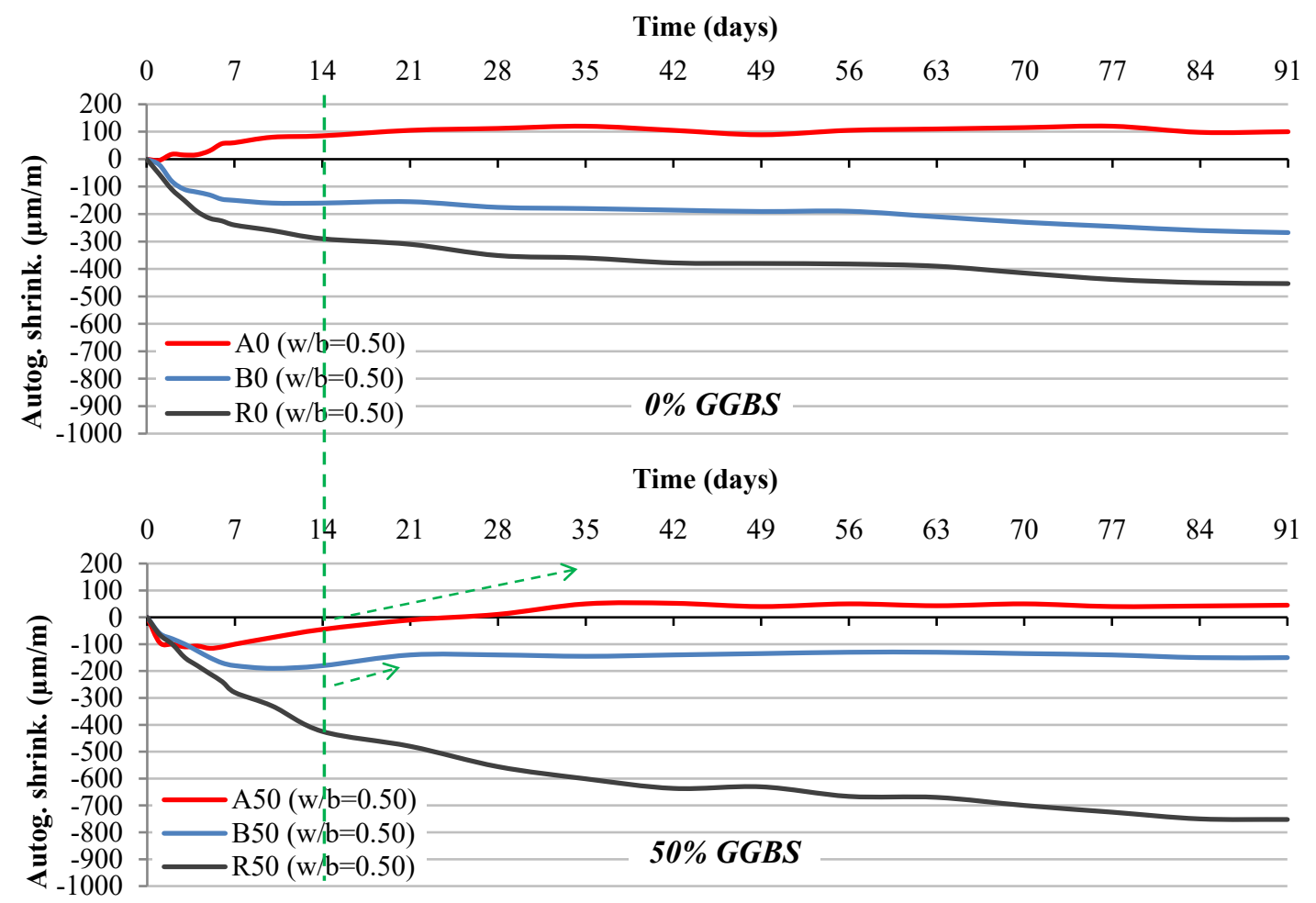

Figure 3. Autogenous shrinkage development of PC-GGBS mortars with SAPs.

Figure 4 shows the progressive reduction of pores with diameter under $20 \mathrm{~nm}$, particularly for samples A50 and B50. GGBS has reacted with water and the formation of hydrated products, deposited in that range of pores, led to the "relative" expansion of SAP mortars. When water was consumed and SAP collapsed, no significant external volume changes were recorded, and AS curves had a tendency to flatten out (around the $42^{\text {nd }}$ day).

Desorption of SAP is mainly controlled by capillary suction in early-ages. After that, there may be a detachment between SAP and pore wall (from the cement matrix) and/or SAP can be built into the wall (and likely covered with hydration products). Thus, SAP moisture can be released to the paste under humidity gradient (in form of vapour) or can be itself a water supplier for continuous curing (Wang, Yang, Hu, Li, \& Cheng, 2016). The water stored by polymer may move through smaller pores since they provide more surface area for water to adhere to. Indeed, there is a preference of GGBS products in precipitating into smaller pores in non-saturated-water condition (Choi, Kim, \& Choi, 2017).

Moreover, GGBS reaction is directly related to the saturation of portlandite $(\mathrm{CH})$ from PC hydration. According to Lothenbach \& Winnefeld (2006), most of $\mathrm{CH}$ is formed during the first $1000 \mathrm{~h}$ hydration (or 42 days). This is approximately when mortars with slag exhibited maximum relative expansion. The maximum amount of $\mathrm{CH}$ means max activation for GGBS hydration, prompting the production of further $\mathrm{C}-\mathrm{S}-\mathrm{H}$. The more $\mathrm{CH}$, the higher is $\mathrm{pH}$ in the vicinity of GGBS grains, and hence the higher is reactivity of slag. These later hydrated products fill extra spaces which were not filled by the cement hydrates due to the lack of clinker (Scrivener, Juilland, et al., 2015). 

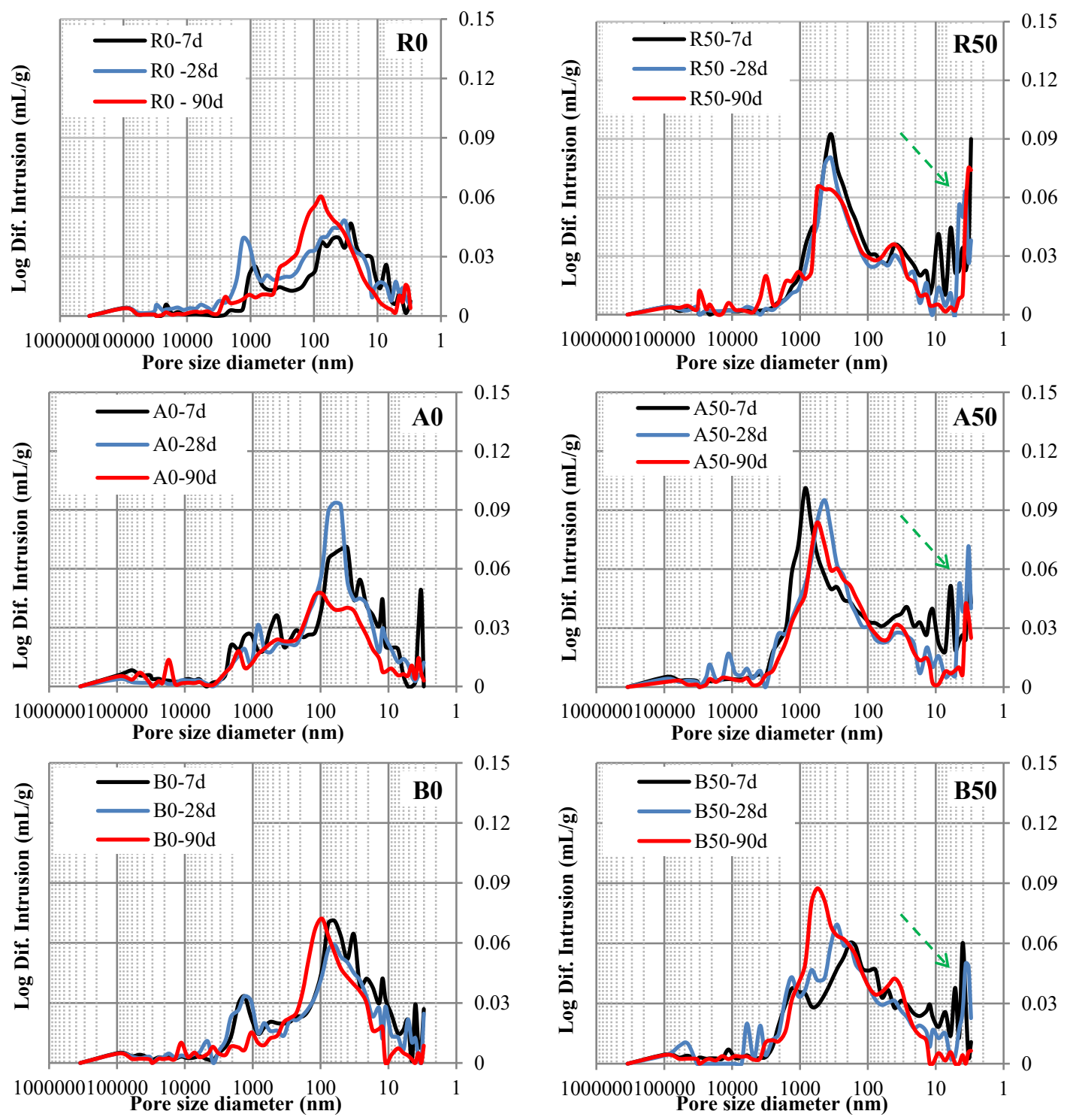

Figure 4. Pore size distribution (by MIP) of PC-GGBS mortars at different ages $(\mathrm{w} / \mathrm{b}=\mathbf{0 . 5 0}$ for all samples).

As smaller pores are being filled with later hydration products, these products start to exert pressure upon pore walls. Due to potential lack of room for C-S-H precipitation, there is a "space competition" between hydrated products and hardened microstructure, and it happens in pores below $20 \mathrm{~nm}$. This outcome seen in Figure 4 is in line with other authors (Berodier \& Scrivener, 2015; Scrivener, Juilland, et al., 2015). Consequently, this stress leads to the "relative" expansion of the hardened bulk volume in later ages, particularly for SAP-PC-GGBS matrices (A50 and B50) after the second week (Almeida \& Klemm, 2018b).

Figure 5 shows a reduction of drying shrinkage (DS) rate in SAP samples as a result of swelling/contraction in the second week. It was more pronounced for mortars with high WAC - SAP A. 


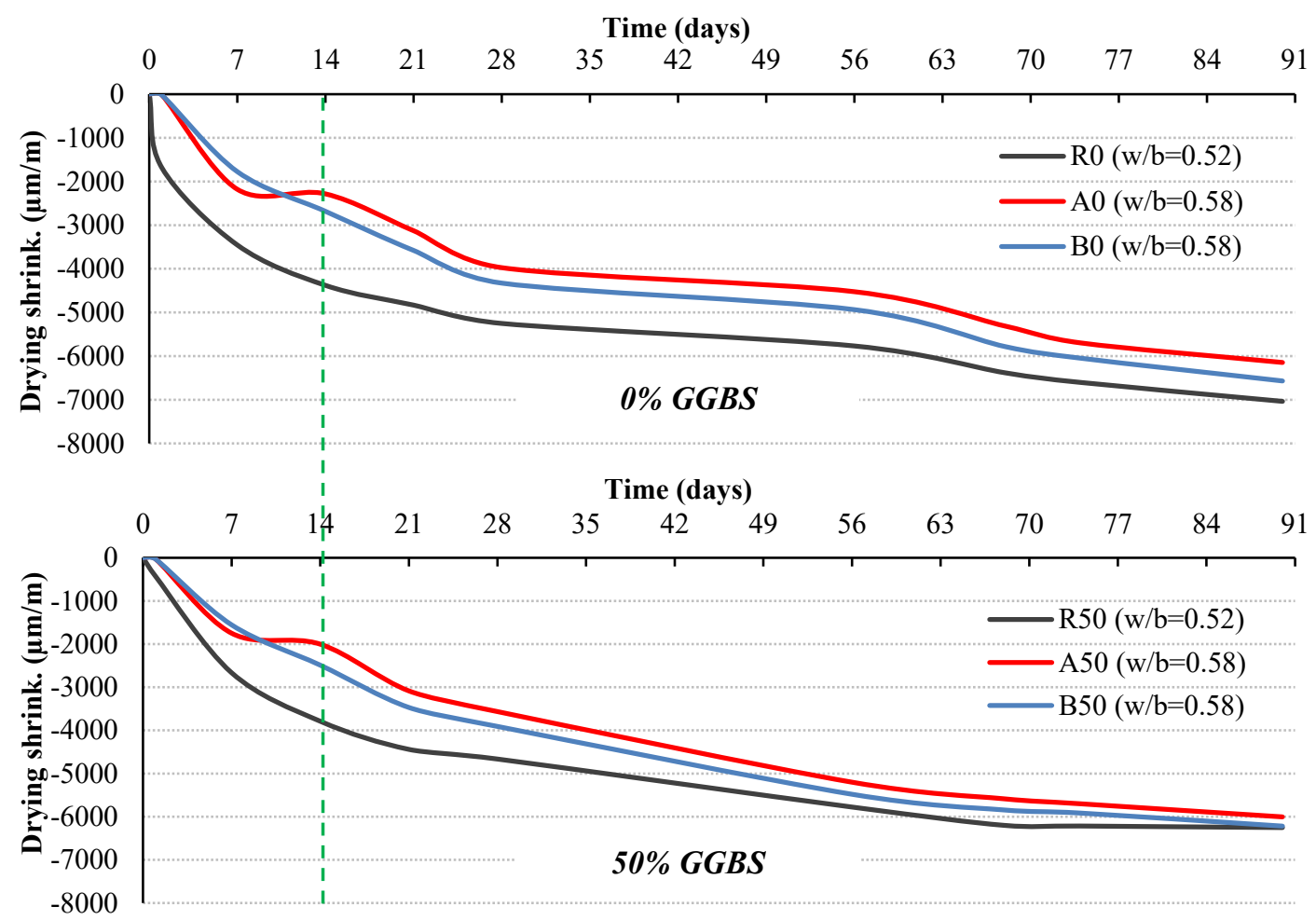

Figure 5. Drying shrinkage development of PC-GGBS mortars with SAPs.

Moreover, even with higher w/c ratios for SAP samples, similar or slightly reduced DS was observed in comparison to the reference sample, confirming the positive effect of SAP in mitigating shrinkage.

\section{CONCLUSIONS}

SAP significantly reduces plastic, autogenous and drying shrinkages. Moreover, SAP can help GGBS hydration, contributing to water supply for further reactions in a prolonged time (up to 90 days). Experimental results indicated that the later GGBS reactions can be facilitated not only by SAP water (that is adhered to smaller pores, with high surface area) but also by the potential presence of portlandite from PC hydration (max $\mathrm{CH}$ saturation is about day 42). Thus, the later hydration products seem to start to form after the second week into the smaller pores (under than $20 \mathrm{~nm}$ ) resulting in an increment of internal compressive stress. This, in turn, may lead to a slight "relative" expansion of the bulk volume of SAP-PC-GGBS systems. This effect is more pronounced for SAP A due to its higher capacity to store water and slower desorption kinetics.

\section{ACKNOWLEDGEMENTS}

The authors acknowledge CNPq/Brazil and FAPEMIG for the financial support (CNPq grant numbers: 204097/2014-2 and 409685/2017-8), BASF for SAPs supply, and Prof Valeria Corinaldesi (UNIVPM-Italy) for plastic shrinkage testing support. 


\section{REFERENCES}

Almeida, F. C. R., Klemm, A. J. (2016). Effect of superabsorbent polymers (SAP) on fresh state mortars with ground granulated blast-furnace slag (GGBS). In 5th International Conference on the Durability of Concrete Structures (pp. 1-7). Shenzhen, 2016.

Almeida, F. C. R., \& Klemm, A. J. (2018a). Effect of GGBS on water absorption capacity and stability of Superabsorbent polymers partially crosslinked with alkalis. Journal of Materials in Civil Engineering, 30(12), 1-11.

Almeida, F. C. R., \& Klemm, A. J. (2018b). Efficiency of internal curing by superabsorbent polymers (SAP) in PC-GGBS mortars. Cement and Concrete Composites, 88, 41-51.

Almeida, F. C. R., Klemm, A. J., \& Corinaldesi, V. (2018). Plastic shrinkage cracking performance of mortars with ground granulated blast-furnace slag (GGBS) modified by superabsorbent polymers (SAP). In PRO 125 - 4th International Conference on Service Life Design for Infrastructures (pp. 1-12). Delft: RILEM.

Berodier, E., \& Scrivener, K. (2015). Evolution of pore structure in blended systems. Cement and Concrete Research, 73, 25-35.

Choi, Y. C., Kim, J., \& Choi, S. (2017). Mercury intrusion porosimetry characterization of micropore structures of high-strength cement pastes incorporating high volume ground granulated blast-furnace slag. Construction and Building Materials, 137, 96-103.

Justs, J., Wyrzykowski, M., Bajare, D. \& Lura, P. (2015). Internal curing by superabsorbent polymers in ultra-high performance concrete. Cement and Concrete Research, 76, 82-90.

Lee, K. M., Lee, H. K., Lee, S. H., \& Kim, G. Y. (2006). Autogenous shrinkage of concrete containing granulated blast-furnace slag. Cement and Concrete Research, 36(7), 12791285.

Lothenbach, B., \& Winnefeld, F. (2006). Thermodynamic modelling of the hydration of Portland cement. Cement and Concrete Research, 36(2), 209-226.

Mechtcherine, V., \& Reinhardt, H.-W. (Eds.). (2012). Application of Superabsorbent Polymers ( SAP ) in Concrete Construction: State-of-the-Art Report Prepared by Technical Committee 225-SAP. RILEM: Springer.

Scrivener, K. L., Juilland, P., \& Monteiro, P. J. M. (2015). Advances in understanding hydration of Portland cement. Cement and Concrete Research, 78, 38-56.

Scrivener, K. L., Lothenbach, B., De Belie, N., Gruyaert, E., Skibsted, J., Snellings, R., \& Vollpracht, A. (2015). TC 238-SCM: hydration and microstructure of concrete with SCMs. Materials and Structures, 48(4), 835-862.

Snoeck, D., Jensen, O. M., \& De Belie, N. (2015). The influence of superabsorbent polymers on the autogenous shrinkage properties of cement pastes with supplementary cementitious materials. Cement and Concrete Research, 74, 59-67.

Wang, F., Yang, J., Hu, S., Li, X., \& Cheng, H. (2016). Influence of superabsorbent polymers on the surrounding cement paste. Cement and Concrete Research, 81, 112-121.

Wyrzykowski, M., Igarashi, S.-I., Lura, P., \& Mechtcherine, V. (2018). Recommendation of RILEM TC 260-RSC: using superabsorbent polymers (SAP) to mitigate autogenous shrinkage. Materials and Structures, 51(135), 1-7. 